\title{
New developments in the management of psoriasis and psoriatic arthritis: a focus on apremilast
}

This article was published in the following Dove Press journal:

Drug Design, Development and Therapy

26 March 2013

Number of times this article has been viewed

\author{
Andrew C Palfreeman \\ Kay E McNamee \\ Fiona E McCann \\ The Kennedy Institute of \\ Rheumatology, Nuffield Department \\ of Orthopedics, Rheumatology and \\ Musculoskeletal Sciences, University \\ of Oxford, London, UK
}

\begin{abstract}
Psoriasis is a chronic inflammatory skin disease, most commonly resulting in the occurrence of red and silver scaly plaques. About $30 \%$ of psoriasis sufferers develop psoriatic arthritis (PsA), a disorder that presents with additional joint inflammation and other clinical features. At present, the most effective treatment for moderate and severe psoriasis and PsA are biologics such as antitumor necrosis factor alpha therapy. Biologics are costly and typically require repeated injections; hence, the development of novel, orally available, small molecular inhibitors that are less expensive to produce is highly desirable. The phosphodiesterase 4 inhibitor apremilast is a small molecular inhibitor that acts by increasing cyclic adenosine monophosphate levels, ultimately suppressing tumor necrosis alpha production. Apremilast has been tested in a number of psoriasis and PsA pilot and Phase II trials to evaluate its efficacy and safety. More recently, three larger double-blinded, and randomized multicenter studies demonstrate that apremilast is efficacious in the treatment of psoriasis and PsA, with significantly higher numbers of apremilast-treated patients achieving endpoints of a 75\% reduction compared to baseline in Psoriasis Area and Severity Index (PASI-75) or American College of Rheumatology-20 scores, relative to placebo. This encouraging data, along with a tolerable incidence of mild to moderate adverse events, has led to the initiation of several large Phase III trials that aim to further validate apremilast as a treatment for psoriasis and PsA. Here, we provide an overview of the current treatments for psoriasis and PsA, and summarize the findings from multiple Phase II clinical trials where the effects of apremilast in the treatment of psoriasis and PsA patients have been investigated.
\end{abstract}

Keywords: apremilast, psoriasis, psoriatic arthritis, phosphodiesterase inhibitor

\section{Introduction}

Taking cues from the largely successful treatment of rheumatoid arthritis (RA) with tumor necrosis factor alpha $(\mathrm{TNF} \alpha)$ blockade, the treatment of psoriasis and psoriatic arthritis (PsA) has been vastly improved in recent years with the development of biologic therapies that target important inflammatory proteins pivotal for disease progression. Whilst efficacious for a substantial number of patients, a number of drawbacks with this course of therapy prevail. High on the list is the necessary route of administration; biologics must be delivered either intravenously or subcutaneously, mostly requiring regular visits to the clinic for dosing. This inconvenience to the patient, coupled with the relatively high manufacturing costs of biologics, drives continued research and the development of improved, orally available therapies that limit disease progression without impacting on patient lifestyle and well-being. This review provides an overview of the current therapies for 
psoriasis and PsA, and the future prospects for new drugs in the pipeline, with special attention given to apremilast (Celgene Corporation, Summit, NJ, USA), a novel, orally available phosphodiesterase 4 (PDE4) inhibitor, which is now in Phase III clinical trials.

Psoriasis is a chronic immune skin disorder that affects $1 \%-3 \%$ of the world's population. Often linked with genetic and environmental triggers, ${ }^{1,2}$ it is characterized by hyperproliferation of the skin's epidermal layer, which is attributed to premature maturation of keratinocytes and dermal inflammatory infiltrates comprising dendritic cells, macrophages and T cells. ${ }^{1,2}$ Affecting $85 \%-90 \%$ of patients, the most prevalent form of psoriasis (psoriasis vulgaris) results in the occurrence of raised plaques with silvery scales that can present on any part of the skin, but are most commonly found on the scalp, back, and the extensor surfaces (elbows and knees) (Figure 1)., ${ }^{2,3}$ While approximately one-third of patients go on to develop PsA, up to $20 \%$ of PsA sufferers develop arthritic symptoms prior to plaque formation. ${ }^{4,5}$ PsA presents additionally with joint inflammation and synovitis, but it is distinct from related joint disorders like RA through the inclusion of enthesitis, dactylitis, and spinal involvement (Figure 1), and it is better characterized as a spondyloarthropathy disorder. ${ }^{4,6}$ Psoriasis and PsA patients often have a poor quality of life ${ }^{2}$ and both diseases have a considerable impact on the economy, with the National Psoriasis Foundation (USA) estimating the direct and indirect costs at over US \$11 billion annually. ${ }^{?}$

A

Healthy skin

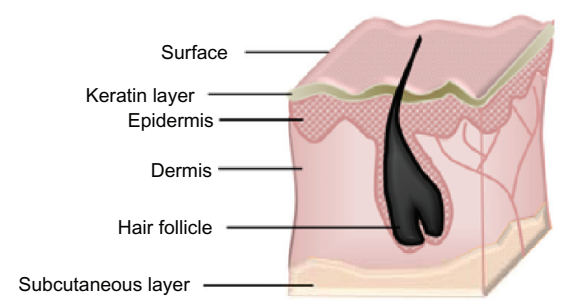

Unsurprisingly, the effective management of psoriasis and PsA is largely dependent on the severity of the disease. Mild psoriatic plaques can be successfully treated topically, with corticosteroids, emollients, coal tar preparations, or vitamin D analog. ${ }^{5}$ For moderate to severe disease, systemic treatments are employed. Initially, patients are often treated with oral therapies such as methotrexate, cyclosporine, and sulfasalazine..$^{5,6,8}$ Failure to respond to these agents can lead to the patient being placed on a biologic, most commonly an anti-TNF $\alpha$ inhibitor (Table 1). Anti-TNF $\alpha$ biologics have been highly successful in the treatment of psoriasis and PsA, with efficacy measured using the Psoriasis Area and Severity Index (PASI). The PASI assesses psoriatic disease by assigning an ascending score to plaques of increasing severity (thickness, redness, and scaling) and the extent of the plaque spread. Psoriasis patients typically achieve a $75 \%$ reduction compared to baseline PASI (PASI-75) in $\sim 70 \%-80 \%$ of cases that are treated with either adalimumab or infliximab. Similarly, $\sim 59 \%-68 \%$ of PsA patients receiving either agent reach PASI-75., $5,6,8,9$ Despite the clear efficacy of anti-TNF $\alpha$ biologics, not all patients respond adequately to treatment. New biologic targets are now being evaluated in the clinic to address this, with a recent focus on targeting Th17 cells (Table 1). Th17 cells are T helper cells defined by their production of interleukin (IL)-17 and require IL-23 for their maintenance. ${ }^{10}$ Brodalumab (Amgen Inc, Thousand Oaks, CA, USA), ixekizumab (Eli Lilly and Company, Indianapolis, IN, USA), and secukinumab

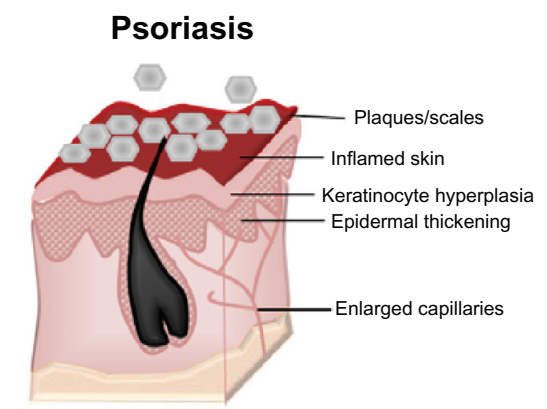

B

\begin{tabular}{l|l} 
Enthesitis & $\begin{array}{l}\text { Inflammation at the site where the tendon enters the bone. } \\
\text { Digit inflammation of the tendon and joint, known as 'sausage finger'. } \\
\text { Occurs in around } 50 \% \text { of PsA patients. } \\
\text { Dactylitis }\end{array}$ \\
Spondylitis & $\begin{array}{l}\text { Inflammation of the sacroiliac and apophyseal joints in the spine. } \\
\text { Ocular inflammation present in } 19 \% \text { of PsA patients. } \\
\text { Conjunctivitis }\end{array}$ \\
Pstting of the nail, nail detachment, thickening and hardening of the nail \\
bed.
\end{tabular}

Figure I Psoriasis and PsA. (A) Psoriasis is associated with a hyperproliferative epidermal layer, abnormal keratinocyte growth, and an inflammatory cell infiltrate including T cells and macrophages. This manifests in inflamed skin and raised plaques with silvery scales and can cover large areas of the body. (B) Glossary of clinical features associated with classification of psoriatic arthritis. Adapted from Bren L. Psoriasis: more than cosmetic. FDA Consumer. 2004 Sept-Oct. Available from: http://permanent.access.gpo. gov/lps I609/www.fda.gov/fdac/features/2004/504_psoriasis.html. Accessed February 8, 2013. ${ }^{63}$

Abbreviation: PsA, psoriatic arthritis. 


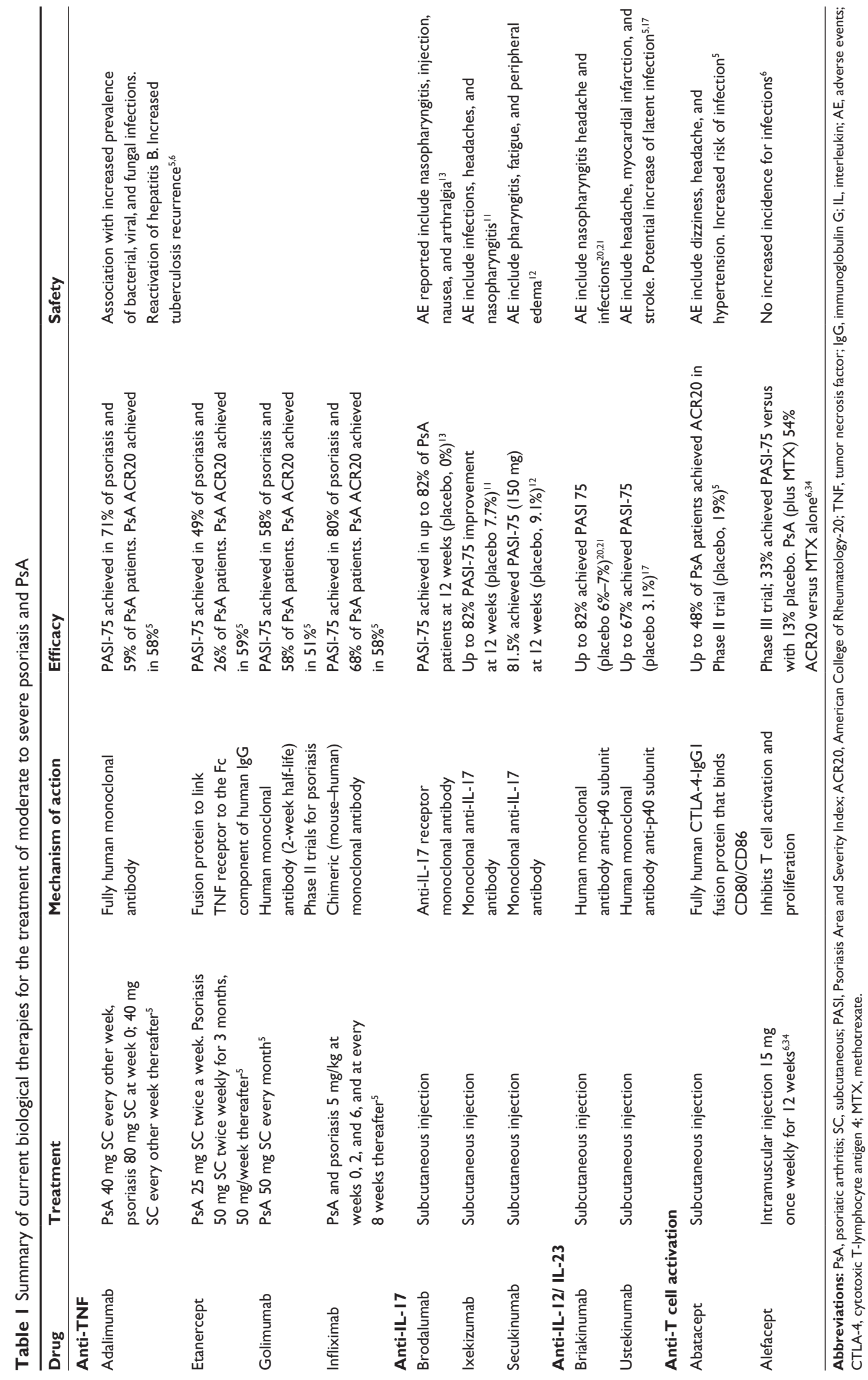


(Novartis Corporation, Basel, Switzerland) are antagonistic antibodies that target IL-17. All have demonstrated efficacy in their initial drug trials, and they are currently being studied in Phase III trials for the treatment of psoriasis and PsA. ${ }^{11-14}$ Targeting related pathways, briakinumab (Abbot Laboratories, Abbott Park, IL, USA) and ustekinumab (Janssen Biotech, Inc, Horsham, PA, USA) inhibit the IL-12/IL-23p40 subunit, and have completed Phase III trials for psoriasis and are currently being evaluated in PsA. ${ }^{15-19}$ Notably, results from an additional 12-week trial suggested that psoriasis patients receiving either ustekinumab or briakinumab had a higher clinical response than patients receiving etanercept, ${ }^{20-22}$ suggesting that these emerging biologics may challenge the dominance of anti-TNF $\alpha$ in psoriasis and PsA if their longterm safety profile is acceptable.

A major disadvantage with biologic therapies is that they must be delivered either subcutaneously or intravenously, and they are expensive, with the cost per patient ranging between US $\$ 15,000-\$ 30,000+$ per year. ${ }^{23}$ Thus, there is a significant need for more cost-effective drugs that can be orally administered that influence proinflammatory cytokines. Small molecular weight inhibitors (SMI compounds with a molecular weight of less than $1 \mathrm{kDa}$ ), have been much explored for their potential to treat autoimmune disorders, with manufacturing costs projected to be significantly less expensive than biologics. ${ }^{24}$ The SMI currently being investigated in inflammatory diseases are largely targeted to intracellular signaling pathways, the most explored of which target kinases. Imperative for cellular processes, kinases are attractive targets as they often act upstream of inflammatory mediators such as TNF $\alpha$, and hence selective blockade can regulate multiple inflammatory processes. ${ }^{25}$ Although many novel kinase inhibitors have been developed in recent times, few have progressed through the clinic. Of these, tofacitinib (Pfizer, Inc, New York, NY, USA) is an oral Janus kinase (JAK) inhibitor that has proven to be efficacious in moderate to severe plaque psoriasis over a 12-week treatment period and is currently in Phase III trials. ${ }^{26,27}$ Tofacitinib is also in Phase IIb trials for PsA after its success in trials with RA patients who had previously failed to respond to biologics; ${ }^{28}$ however, concerns were raised over toxicity when four patients enrolled in the RA Phase III multicenter studies died, where one of these deaths due to respiratory failure was attributed to the drug. ${ }^{29}$ Adding to the concern, a recent study has suggested a link between tofacitinib and reactivation of tuberculosis in a mouse model, further highlighting the need for more thorough investigation into its safety. ${ }^{30}$ Another oral JAK1/2 inhibitor, baricitinib (Eli Lilly and Company; Incyte Corporation, Wilmington, DE, USA), is currently being evaluated in a Phase IIb study for patients with moderate to severe psoriasis, and primary results are expected in $2013 .^{31}$

\section{PDE4 inhibition and apremilast}

Although research for oral treatments has been largely dominated by kinase targets, other SMI-targeting alternative pathways are in development, including those designed to inhibit PDE4. Phosphodiesterases comprise a family of enzymes that uniquely hydrolyse and degrade cyclic adenosine monophosphate (cAMP). One of eleven subtypes, PDE4, is widely expressed in numerous cell types, including hematopoietic cells, keratinocytes, endothelial cells, as well as muscle and nerve cells. ${ }^{32,33}$ Amongst its various cellular functions, including roles in apoptosis and lipid metabolism, PDE4 regulates immune and inflammatory processes through control of intracellular cAMP levels and downstream protein kinase A pathways. ${ }^{34}$ In turn, the production of a number of key inflammatory cytokines by myeloid and lymphoid cells is affected, shaping the immune response accordingly.

Specific inhibition of PDE4 in human peripheral monocytes by a number of agents causes decreased production of LPS-induced TNF $\alpha .{ }^{35}$ Monocytes and macrophages chronically treated with ethanol showed increased expression of PDE4B, reduced expression of cAMP, and increased nuclear factor kappa beta (NFKB) signaling, ultimately leading to an increase in lipopolysaccharide-stimulated TNF $\alpha$ production. This effect was abolished by the addition of the classical PDE4 inhibitor, rolipram, highlighting the potential of this class of drug to control NFKB-mediated immune processes. ${ }^{36}$ Intriguingly, such effects are not restricted to the control of proinflammatory mediators. Inhibition of PDE4 has been demonstrated to elevate the anti-inflammatory cytokine IL-10 via protein kinase A-mediated protein interactions with cAMP response elements in the promoter and enhancer regions of the $I L-10$ gene..$^{37,38}$ Thus, the outcome of limiting PDE4 activity is contextually dependent on effector gene expression and the proximity of $\mathrm{NF} \kappa \mathrm{B}$ or cAMP response elements in promoter regions. Additionally, PDE4 activity augments effector function in lymphocytes and neutrophils. Inhibition with rolipram suppresses antigen-induced $\mathrm{T}$ cell proliferation and cytokine production, ${ }^{39}$ while PDE4 inhibition decreases the production of IL-8, a major chemoattractant for neutrophils. Furthermore, PDE4 increases expression of the B2-integrin Mac-1 on neutrophils, associated with activation and extravasation across endothelial linings. ${ }^{33}$ Thus, the potential of a selective PDE4 inhibitor to control 
unwarranted immune responses, pertinent to autoimmunity, is clear. Many of the cytokine mediators of psoriasis and PsA are influenced by PDE4 activity; therefore, specific inhibitors could be beneficial, as previously reviewed. ${ }^{40,41}$ Celgene has developed apremilast (CC-10004; Celgene Corporation), a novel, orally available small molecule that specifically targets PDE4. Effects on lipopolysaccharide-stimulated human peripheral blood mononuclear cells demonstrated the attenuation of a number of cytokines including IFN $\gamma$, TNF $\alpha$, IL-12, and IL-23, and the chemokines CXCL9 and CXCL10. ${ }^{41}$ Importantly, this study has also demonstrated the potential of apremilast to restrict TNF $\alpha$ production from keratinocytes and natural killer cells, the major constituent of psoriatic skin lesions. ${ }^{40,42}$

Recently, in vivo experiments conducted in a classical preclinical model of psoriasis, using normal human skin xenotransplanted onto severe combined immunodeficiency mice, injected with human natural killer cells from psoriatic donors, strongly support a therapeutic role for PDE4 blockade. Orally administered apremilast significantly reduced epidermal thickness and decreased histopathological features of psoriasis plaques. ${ }^{41}$ While many mouse models of psoriasis have been described, ${ }^{43}$ an equivalent model for PsA combining skin lesions and spondyloarthropathies has not been described. However, the therapeutic effect of apremilast and other PDE4 inhibitors has been tested in human rheumatoid synovial cells and in animal models of arthritis. ${ }^{44,45}$ Inhibitory effects on the spontaneous production of TNF $\alpha$, IL-1b, and chemokines MCP-1, MIP-1 $\alpha$, MIP-1 $\beta$, and RANTES from RA synovial cells were observed in the presence of roflumilast (Takeda Pharmaceutical Company Limited, Osaka, Japan) and two novel PDE4 inhibitors (INH0061 and INH0062; GlaxoSmithKline Inc, London, UK). Similarly, at $0.25 \mathrm{nM}$ to $100 \mathrm{nM}$ concentrations, apremilast dose-dependently inhibited the spontaneous production of TNF $\alpha$ from RA synovial membrane cultures, showing a similar efficacy to the classic PDE4 inhibitor, rolipram. ${ }^{45}$ In classical collageninduced arthritis in dilute brown non-agouti/1 (DBA/1) mice, clinical and histopathological signs of disease were reduced with daily intraperitoneal injections of $5 \mathrm{mg} / \mathrm{kg}$ or $25 \mathrm{mg} /$ $\mathrm{kg}$. Such effects were reproduced in an alternative model of collagen antibody-induced arthritis in BALB/c mice, receiving an oral dose of $25 \mathrm{mg} / \mathrm{kg}$ apremilast daily.

\section{Assessment of apremilast in the clinic}

Having demonstrated the capacity to suppress TNF $\alpha$ in vivo, and indications that it was well tolerated by naïve mice in terms of lethargy relative to those dosed with rolipram, ${ }^{45}$ apremilast held significant promise when entering Phase II clinical trials. Since the early development of PDE4 inhibitors, one of the main concerns has been the associated adverse events (AE). These side effects tend to primarily affect the gastrointestinal system, resulting in nausea and emesis, as well headaches. ${ }^{34}$ It has been shown that these AE are a result of the inhibition of the PDE4D isoform. ${ }^{46}$ Interestingly, apremilast does not selectively inhibit any specific isoform of PDE4, ${ }^{47}$ but it does appear to be void of these typical complications, and the majority of reported AE are classed as "mild to moderate" by investigators.

The total number of clinical trials involving apremilast currently stands at 39 . These include small Phase I trials and pilot studies investigating efficacy in a number of conditions including atopic dermatitis, erythematotelangiectatic rosacea, acne, acute gout, uveitis, vulvodynia, and prurigo nodularis. ${ }^{48}$ Nine studies have published their results and are summarized in Table 2. There are a total of four published trials assessing the efficacy of apremilast in psoriasis or PsA, which we will look at in this review. Amongst the completed Phase II trials, three stand out due to the substantially higher number of enrolled participants, exceeding 200 in each study. These trials were well conducted and contained patients displaying similar demographic and baseline characteristics between the randomized groups. Strikingly, all three have yielded positive results when testing apremilast against placebo, as well as displaying a dose-dependent effectiveness in both psoriasis and PsA. ${ }^{49-51}$ The first trial of apremilast in the treatment of psoriasis was published in 2008..$^{52}$ Eight out of the 19 patients receiving apremilast achieved the primary endpoint of a reduction in epidermal thickness of $\geq 20 \%$ (classified as responders), with one other patient reaching a $19.9 \%$ reduction. Four other patients experienced reductions of $<20 \%$. Accompanying the positive clinical response, a decreased number of T cells and CD11c-expressing cells in the dermis and epidermis was observed in responders, thus illustrating apremilast's potential biological activity. In this study, 14 of the 19 patients $(73.7 \%)$ saw an improvement in their disease state according to their PASI score. At least one AE (the most common being nausea and headaches) was observed in 14 patients (73.7\%), but most of these were classified as mild by the investigators. While this study involved only a small number of patients, it demonstrates the ability of apremilast to successfully and safely treat psoriasis in some patients.

The two largest Phase II trials investigating the effectiveness of apremilast in psoriasis treatment were led by Dr Kim Papp et al. ${ }^{49,50}$ Each trial has been double-blinded and involved a robust number of participants, 259 and 352 respec- 


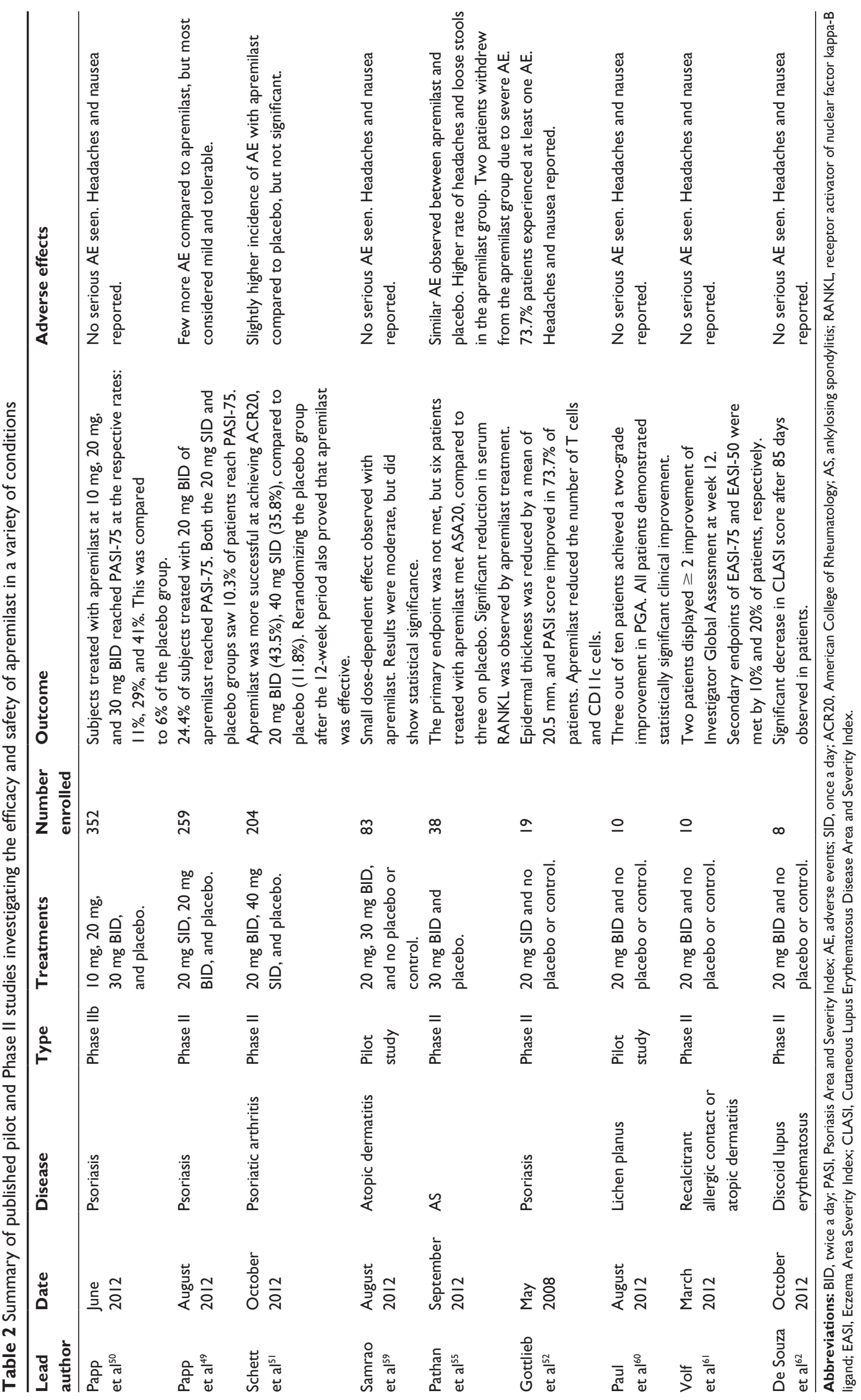


tively, across multiple sites. The first study was conducted between April 2006 and May 2007 across 30 sites in Canada, ${ }^{50}$ as well as in the Czech Republic and Germany. The investigators compared apremilast at doses of $20 \mathrm{mg}$ once daily (SID), $20 \mathrm{mg}$ twice daily (BID), and a placebo. Employing the endpoint of PASI-75, only the higher dose (20 mg BID) was significantly more effective than placebo, with efficacy observed in 21 out of 86 patients (24.4\%), compared to nine out of 87 patients (10.3\%) for both the apremilast $20 \mathrm{mg}$ SID and placebo group. When applying a PASI-50 endpoint, the results of the apremilast $20 \mathrm{mg}$ BID group improved to 49 out of 86 patients (57.0\%), and the apremilast $20 \mathrm{mg}$ SID group to 24 out of 87 patients (27.6\%) meeting the target, suggestive of a dose-dependent response. Both treatment regimens provided enhanced efficacy over the placebo where 20 out of 87 patients (23.0\%) reached PASI-50. No serious AE were seen, and both doses of apremilast were well tolerated. The most common AE recorded were headaches, nasopharyngitis, diarrhea, and nausea. This study clearly demonstrated that apremilast is effective at treating moderate to severe psoriasis. Given that no serious AE were seen with a dose of $20 \mathrm{mg}$ $\mathrm{BID}$, and considering the dose-dependent results that were indicated, Papp et al ${ }^{50}$ suggested a higher dose could be used in future trials.

Following on, the second of Papp et al's clinical trials, ${ }^{49}$ which was also conducted across multiple sites in the USA and Canada, investigated a dosing regimen of $10 \mathrm{mg}, 20 \mathrm{mg}$, and $30 \mathrm{mg}$ BID versus placebo in a total of 352 patients suffering from moderate to severe psoriasis. Again, the primary endpoint was PASI-75, but this time the study was extended from 12 to 16 weeks. A total of $6 \%$ of the placebo group reached PASI- 75 compared to $11 \%, 29 \%$, and $41 \%$ of the $10 \mathrm{mg}, 20 \mathrm{mg}$, and $30 \mathrm{mg}$ groups, respectively. The two highest doses were significantly efficacious when compared to placebo, unequivocally illustrating the dose-dependent characteristics of apremilast as suggested in the first of Papp's clinical trials. An additional dimension to this trial involved the placebo group being placed on either $20 \mathrm{mg}$ or $30 \mathrm{mg}$ BID of apremilast at week 16 for a further 8 weeks. The improvement in PASI score in these patients was rapid and by week 24 the mean change from baseline was on par with patients that had started treatment with $20 \mathrm{mg}$ or $30 \mathrm{mg}$ BID of apremilast at week 0. Apremilast was effective in reducing disease severity in a number of other measurements, including Dermatology Life Quality Index scores and the Short Form-36 mental component summary scores. During the first 16-week period of the trial, 255 out of 352 patients $(72.4 \%)$ suffered at least one $\mathrm{AE}$, and during the period of weeks $16-24$ the ratio changed to 121 out of $280(43.2 \%)$. Of these, most were considered to be mild to moderate.

Another encouraging Phase II clinical trial investigating the effect of apremilast in the treatment of PsA was led by Professor Georg Schett in Germany. ${ }^{51}$ In this trial, 204 patients received either $20 \mathrm{mg}$ BID, $40 \mathrm{mg}$ SID, or placebo. The primary endpoint was the achievement of a $20 \%$ reduction in disease according to the American College of Rheumatology criteria (ACR20). In all, 165 patients completed the treatment phase (12 weeks) and $11.8 \%$ of the placebo group reached ACR20, compared to $43.5 \%$ of the $20 \mathrm{mg}$ BID group and $35.8 \%$ of the $40 \mathrm{mg}$ SID group. Further to this, patients that were receiving placebo were then rerandomized at week 12 to receive either $20 \mathrm{mg}$ BID or $40 \mathrm{mg}$ SID of apremilast for another 12 weeks. By week 24 in both apremilast groups $>40 \%$ had achieved ACR20. While this data is positive, more trials in PsA are required to assess the limitations of apremilast. When evaluating ACR20, the ratio of success was 11.8\%:43.5\%:35.8\% (placebo:apremilast $20 \mathrm{mg}$ BID: apremilast $40 \mathrm{mg}$ SID) after the treatment phase. Although it is difficult to conclude until a direct comparison is conducted, the success rate of apremilast in this study is less than that observed for anti-TNF $\alpha$ treatment of PsA (51\%-59\% meet ACR20; see Table 1), thus highlighting that more needs to be done to establish whether apremilast confers overall benefits compared to currently available biologics.

To date, there are nine Phase III clinical trials underway at several sites, which are due for completion from 2014 onwards (listed in Table 3); the majority of these trials are assessing the effects of multiple doses of apremilast in treating patients with PsA, psoriasis, ankylosing spondylitis (AS), sarcoidosis, and cutaneous sarcoidosis (summarized in Table 3).

While this review is focusing on the treatment of psoriasis and PsA, the documented effects of apremilast in the treatment of related autoimmune diseases such as RA and AS are noteworthy. Although three Phase II trials have been registered to assess the safety and effectiveness of apremilast in RA patients, none have so far yielded results. Two trials that were initiated in 2010 (NCT01285310 and NCT01204138) have not yet published the results. Recruitment is ongoing for a third Phase II trial (NCT01250548), and therefore it remains too early to ascertain the efficacy of apremilast in RA. ${ }^{48}$ Perhaps more akin to PsA is the related spondyloarthropathy, AS. Genetic studies have revealed an association between psoriasis and AS with common susceptibility genes $I L-23 R, I L-12 B$, STAT3, and CARD9..$^{53,54}$ Due to the similarities in genetics and clinical manifestations, it was 
Table 3 Summary of registered Phase III clinical trials investigating the effectiveness of apremilast to treat psoriasis, psoriatic arthritis, ankylosing spondylitis, and sarcoidosis ${ }^{58}$

\begin{tabular}{|c|c|c|c|c|c|}
\hline $\begin{array}{l}\text { Trial } \\
\text { name }\end{array}$ & NCT number & Disease & Treatments & $\begin{array}{l}\text { Number } \\
\text { enrolled }\end{array}$ & $\begin{array}{l}\text { Completion } \\
\text { date }\end{array}$ \\
\hline PALACE-I & NCT0II 72938 & Psoriatic arthritis & $20 \mathrm{mg}, 30 \mathrm{mg}$, placebo $+20 \mathrm{mg}$, placebo $+30 \mathrm{mg}$ (all BID) & 495 & September 2015 \\
\hline PALACE-2 & NCT0I 212757 & Psoriatic arthritis & $20 \mathrm{mg}, 30 \mathrm{mg}$, placebo + $20 \mathrm{mg}$, placebo + $30 \mathrm{mg}$ (all BID) & 495 & November 2015 \\
\hline PALACE-3 & NCTOI 212770 & Psoriatic arthritis & $20 \mathrm{mg}, 30 \mathrm{mg}$, placebo $+20 \mathrm{mg}$, placebo $+30 \mathrm{mg}$ (all BID) & 495 & November 2015 \\
\hline PALACE-4 & NCT0I307423 & Psoriatic arthritis & $20 \mathrm{mg}, 30 \mathrm{mg}$, placebo $+20 \mathrm{mg}$, placebo $+30 \mathrm{mg}$ (all BID) & 495 & March 2014 \\
\hline ESTEEM I & NCTOII94219 & Plaque psoriasis & $30 \mathrm{mg}$ BID and placebo & 844 & November 2016 \\
\hline ESTEEM 2 & NCTOI 232283 & Plaque psoriasis & $30 \mathrm{mg}$ BID and placebo & 413 & December 2016 \\
\hline- & NCT0I690299 & Plaque psoriasis & $\begin{array}{l}30 \mathrm{mg} \text { BID, etanercept } 50 \mathrm{mg} \text { once weekly, } \\
\text { placebo (tablet), placebo (injection, once weekly) }\end{array}$ & 240 & August 2015 \\
\hline POSTURE & NCT0I583374 & Ankylosing spondylitis & 20 mg, 30 mg, placebo (all BID) & 456 & December 2018 \\
\hline- & NCT00794274 & $\begin{array}{l}\text { Sarcoidosis; cutaneous } \\
\text { sarcoidosis }\end{array}$ & $20 \mathrm{mg}$ BID, no placebo & 20 & December 20II \\
\hline
\end{tabular}

Abbreviations: NCT, National Clinical Trial; PALACE, Efficacy and Safety Study of Apremilast to Treat Active Psoriatic Arthritis; BID, twice a day; ESTEEM, Study to Evaluate Safety and Effectiveness of Oral Apremilast (CC-10004) in Patients with Moderate to Severe Plaque Psoriasis; POSTURE, Study of Apremilast to Treat Subjects with Active Ankylosing Spondylitis.

therefore pertinent to investigate whether apremilast could also be beneficial to AS patients. Most recently, Pathan et a ${ }^{55}$ published a well-executed, but small, study to evaluate the efficacy and safety of apremilast in AS treatment. While the 19 patients assigned to the apremilast group (30 mg BID) failed to reach the primary endpoint (a significant change in the mean Bath Ankylosing Spondylitis Disease Activity Index), the investigators did report general improvement in all clinical assessments; however, none of these clinical improvements reached statistical significance. Investigators also looked at certain biomarkers associated with osteoporosis in patient serum. They reported a significant decrease in serum receptor activator of nuclear factor kappa-B ligand (RANKL) and sclerostin. RANKL inhibition is known to reduce bone erosion in arthritis models. ${ }^{56}$ There was also an observed decrease in the RANKL: osteoprotegerin ratio, reported to be associated with reduced bone mineral density. ${ }^{57}$ Along with tolerable AE, these interesting findings support the rationale for a larger study in AS to be conducted.

\section{Discussion}

Data from three large-scale, multicenter Phase II clinical trials report apremilast to be both efficacious and well tolerated in the treatment of psoriasis and PsA. It has proven successful in achieving PASI-75 in some patients (the most widely used clinical assessment for psoriasis) in these studies, and has been consistently more efficacious than placebo in each case. However, the percentages of patients reaching PASI-75 or ACR20, even at higher doses of apremilast, are not on par with those treated with biologics. Apremilast treatment sees a maximum of $41 \%$ psoriasis patients reach PASI- $75,{ }^{48}$ compared to $71 \%$ treated with adalimumab, and $80 \%$ of those treated with infliximab (Table 1). It is also worth noting that emerging biological therapies are proving to be effective. Anti-IL-17 therapies see $75 \%-86 \%$ of psoriasis patients reach PASI-75, and anti-IL-12/23 therapies are successful in reaching the same endpoint in $67 \%-82 \%$ of psoriasis patients. Apremilast has consistently displayed a dose-dependent profile; the difference in efficacy between doses warrants the investigation of higher doses. While many patients treated with apremilast still suffer AE, they tend to be mild in severity. The ongoing Phase III trials will go some way to thoroughly determine whether efficacy outweighs the AE profile, to qualify apremilast to be the first PDE4 inhibitor licensed for treatment of psoriasis and PsA. At present, the data available indicates that apremilast is not as effective as the biological therapies currently in use. However, the only fair test is a side-by-side comparison, such as the phase III trial currently underway in North America, Belgium, and Netherlands (NCT01690299), which is directly comparing the effects of apremilast with etanercept for treatment of psoriasis. ${ }^{58}$ It is the only Phase III trial that included a biologic as a comparator, as opposed to just a placebo. In addition to efficacy, this head-to-head comparison will be crucially informative on the relative intensity of AE and tolerability. At present, biologics are the leading treatment for moderate to severe psoriasis and PsA. Provided that AE remain mild and well tolerated, and given the lower costs and oral availability, the further clinical development of apremilast seems assured if efficacy proves to be on par with TNF inhibitors. That has yet to be proven, and until the ongoing Phase III trials can be evaluated, the future of apremilast for the treatment of psoriasis and PsA is uncertain. 


\section{Disclosure}

The authors report no conflicts of interest in this work.

\section{References}

1. Nestle FO, Kaplan DH, Barker J. Psoriasis. N Engl J Med. 2009;361(5): 496-509.

2. Gottlieb AB. Psoriasis: emerging therapeutic strategies. Nat Rev Drug Discov. 2005;4(1):19-34.

3. Griffiths CE, Barker JN. Pathogenesis and clinical features of psoriasis. Lancet. 2007;370(9583):263-271.

4. Gladman DD. Psoriatic arthritis. Dermatol Ther. 2009;22(1):40-55.

5. Chang CA, Gottlieb AB, Lizzul PF. Management of psoriatic arthritis from the view of the dermatologist. Nat Rev Rheumatol. 2011;7(10): 588-598.

6. Myers WA, Gottlieb AB, Mease P. Psoriasis and psoriatic arthritis: clinical features and disease mechanisms. Clin Dermatol. 2006;24(5): 438-447.

7. Melnikova I. Psoriasis market. Nat Rev Drug Discov. 2009;8(10): 767-768.

8. Weger W. Current status and new developments in the treatment of psoriasis and psoriatic arthritis with biological agents. Br J Pharmacol. 2010;160(4):810-820.

9. Gottlieb A, Korman NJ, Gordon KB, et al. Guidelines of care for the management of psoriasis and psoriatic arthritis: Section 2. Psoriatic arthritis: overview and guidelines of care for treatment with an emphasis on the biologics. J Am Acad Dermatol. 2008;58(5):851-864.

10. Korn T, Bettelli E, Oukka M, Kuchroo VK. IL-17 and Th17 Cells. Annu Rev Immunol. 2009;27:485-517.

11. Leonardi C, Matheson R, Zachariae C, et al. Anti-interleukin-17 monoclonal antibody ixekizumab in chronic plaque psoriasis. $N$ Engl J Med. 2012;366(13):1190-1199.

12. Papp KA, Langley RG, Sigurgeirsson B, et al. Efficacy and safety of secukinumab in the treatment of moderate-to-severe plaque psoriasis: a randomized, double-blind, placebo-controlled phase II dose-ranging study. Br J Dermatol. Epub October 27, 2012.

13. Papp KA, Leonardi C, Menter A, et al. Brodalumab, an anti-interleukin17-receptor antibody for psoriasis. N Engl J Med. 2012;366(13): 1181-1189.

14. Garber K. Anti-IL-17 mAbs herald new options in psoriasis. Nat Biotechnol. 2012;30(6):475-477.

15. Gottlieb A, Menter A, Mendelsohn A, et al. Ustekinumab, a human interleukin 12/23 monoclonal antibody, for psoriatic arthritis: randomised, double-blind, placebo-controlled, crossover trial. Lancet. 2009; 373(9664):633-640.

16. Papp KA, Langley RG, Lebwohl M, et al; for PHOENIX 2 study investigators. Efficacy and safety of ustekinumab, a human interleukin-12/23 monoclonal antibody, in patients with psoriasis: 52 -week results from a randomised, double-blind, placebo-controlled trial (PHOENIX 2). Lancet. 2008;371(9625):1675-1684.

17. Leonardi CL, Kimball AB, Papp KA, et al; for PHOENIX 1 study investigators. Efficacy and safety of ustekinumab, a human interleukin-12/23 monoclonal antibody, in patients with psoriasis: 76-week results from a randomised, double-blind, placebo-controlled trial (PHOENIX 1). Lancet. 2008;371(9625):1665-1674.

18. Goldminz AM, Gottlieb AB. Ustekinumab for psoriasis and psoriatic arthritis. J Rheumatol Suppl. 2012;89:86-89.

19. Gordon KB, Langley RG, Gottlieb AB, et al. A phase III, randomized, controlled trial of the fully human IL-12/23 mAb briakinumab in moderate-to-severe psoriasis. J Invest Dermatol. 2012;132(2): 304-314

20. Strober BE, Crowley JJ, Yamauchi PS, Olds M, Williams DA. Efficacy and safety results from a phase III, randomized controlled trial comparing the safety and efficacy of briakinumab with etanercept and placebo in patients with moderate to severe chronic plaque psoriasis. Br J Dermatol. 2011;165(3):661-668.
21. Gottlieb AB, Leonardi C, Kerdel F, Mehlis S, Olds M, Williams DA. Efficacy and safety of briakinumab vs etanercept and placebo in patients with moderate to severe chronic plaque psoriasis. $\mathrm{Br} J$ Dermatol. 2011;165(3):652-660.

22. Lin VW, Ringold S, Devine EB. Comparison of ustekinumab with other biological agents for the treatment of moderate to severe plaque psoriasis: a Bayesian network meta-analysis. Arch Dermatol. 2012:1-8.

23. Liu Y, Wu EQ, Bensimon AG, et al. Cost per responder associated with biologic therapies for Crohn's disease, psoriasis, and rheumatoid arthritis. Adv Ther. 2012;29(7):620-634.

24. Stanczyk J, Ospelt C, Gay S. Is there a future for small molecule drugs in the treatment of rheumatic diseases? Curr Opin Rheumatol. 2008;20(3):257-262.

25. Bonilla-Hernán MG, Miranda-Carús ME, Martin-Mola E. New drugs beyond biologics in rheumatoid arthritis: the kinase inhibitors. Rheumatology (Oxford). 2011;50(9):1542-1550.

26. Papp KA, Menter A, Strober B, et al. Efficacy and safety of tofacitinib, an oral Janus kinase inhibitor, in the treatment of psoriasis: a Phase $2 \mathrm{~b}$ randomized placebo-controlled dose-ranging study. $\mathrm{Br} J$ Dermatol. 2012;167(3):668-677.

27. Pfizer. A one-year study to evaluate the effects and safety of CP-690,550 in patients with moderate to severe chronic plaque psoriasis. In: ClinicalTrials.gov [website on the Internet]. Bethesda, MD: US National Library of Medicine; 2011 [updated December 24, 2012]. Available from: http://www. clinicaltrials.gov/ct2/show/NCT01276639?term = tofacitinib + psoriasis \& recr $=$ Recruiting\&phase $=2 \&$ rank $=1$. NLM identifier: NCT01276639. Accessed February 8, 2013.

28. Fleischmann R, Cutolo M, Genovese MC, et al. Phase IIb dose-ranging study of the oral JAK inhibitor tofacitinib (CP-690,550) or adalimumab monotherapy versus placebo in patients with active rheumatoid arthritis with an inadequate response to disease-modifying antirheumatic drugs. Arthritis Rheum. 2012;64(3):617-629.

29. Garber K. Pfizer's JAK inhibitor sails through phase 3 in rheumatoid arthritis. Nat Biotechnol. 2011;29(6):467-468.

30. Maiga M, Lun S, Guo H, Winglee K, Ammerman NC, Bishai WR. Risk of tuberculosis reactivation with tofacitinib (CP-690550). J Infect Dis. 2012;205(11):1705-1708.

31. Eli Lilly and Company. A study in participants with rheumatoid arthritis on background methotrexate therapy. In: ClinicalTrials.gov [website on the Internet]. Bethesda, MD: US National Library of Medicine; 2010 [updated September 18, 2012]. Available from http://www.clinicaltrials. gov/ct2/show/NCT01185353?term=baricitinib\&rank=7. NLM identifier: NCT01185353. Accessed February 8, 2013.

32. Conti M, Beavo J. Biochemistry and physiology of cyclic nucleotide phosphodiesterases: essential components in cyclic nucleotide signaling. Annu Rev Biochem. 2007;76:481-511.

33. Houslay MD, Schafer P, Zhang KY. Keynote review: phosphodiesterase-4 as a therapeutic target. Drug Discov Today. 2005;10(22):1503-1519.

34. Page CP, Spina D. Phosphodiesterase inhibitors in the treatment of inflammatory diseases. Handb Exp Pharmacol. 2011;204:391-414.

35. Seldon PM, Barnes PJ, Meja K, Giembycz MA. Suppression of lipopolysaccharide-induced tumor necrosis factor-alpha generation from human peripheral blood monocytes by inhibitors of phosphodiesterase 4: interaction with stimulants of adenylyl cyclase. Mol Pharmacol. 1995;48(4):747-757.

36. Gobejishvili L, Barve S, Joshi-Barve S, McClain C. Enhanced PDE4B expression augments LPS-inducible TNF expression in ethanolprimed monocytes: relevance to alcoholic liver disease. Am J Physiol Gastrointest Liver Physiol. 2008;295(4):G718-G724.

37. Eigler A, Siegmund B, Emmerich U, Baumann KH, Hartmann G, Endres S. Anti-inflammatory activities of cAMP-elevating agents: enhancement of IL-10 synthesis and concurrent suppression of TNF production. J Leukoc Biol. 1998;63(1):101-107.

38. Platzer C, Fritsch E, ElsnerT, Lehmann MH, Volk HD, Prösch S. Cyclic adenosine monophosphate-responsive elements are involved in the transcriptional activation of the human IL-10 gene in monocytic cells. Eur J Immunol. 1999;29(10):3098-3104. 
39. Essayan DM, Huang SK, Kagey-Sobotka A, Lichtenstein LM. Differential efficacy of lymphocyte- and monocyte-selective pretreatment with a type 4 phosphodiesterase inhibitor on antigen-driven proliferation and cytokine gene expression. J Allergy Clin Immunol. 1997;99(1 Pt 1):28-37.

40. Bos JD, de Rie MA, Teunissen MB, Piskin G. Psoriasis: dysregulation of innate immunity. Br J Dermatol. 2005;152(6):1098-1107.

41. Schafer PH, Parton A, Gandhi AK, et al. Apremilast, a cAMP phosphodiesterase-4 inhibitor, demonstrates anti-inflammatory activity in vitro and in a model of psoriasis. Br J Pharmacol. 2010;159(4):842-855.

42. Cameron AL, Kirby B, Fei W, Griffiths CE. Natural killer and natural killer-T cells in psoriasis. Arch Dermatol Res. 2002;294(8):363-369.

43. Wagner EF, Schonthaler HB, Guinea-Viniegra J, Tschachler E. Psoriasis: what we have learned from mouse models. Nat Rev Rheumatol. 2010;6(12):704-714.

44. Crilly A, Robertson SE, Reilly JH, et al. Phosphodiesterase 4 (PDE4) regulation of proinflammatory cytokine and chemokine release from rheumatoid synovial membrane. Ann Rheum Dis. 2011;70(6): 1130-1137.

45. McCann FE, Palfreeman AC, Andrews M, et al. Apremilast, a novel PDE4 inhibitor, inhibits spontaneous production of tumour necrosis factor-alpha from human rheumatoid synovial cells and ameliorates experimental arthritis. Arthritis Res Ther. 2010;12(3):R107.

46. Cherry JA, Davis RL. Cyclic AMP phosphodiesterases are localized in regions of the mouse brain associated with reinforcement, movement, and affect. J Comp Neurol. 1999;407(2):287-301.

47. Schafer P. Apremilast mechanism of action and application to psoriasis and psoriatic arthritis. Biochem Pharmacol. 2012;83(12):1583-1590.

48. ClinicalTrials.gov [webpage on the Internet]. Search of: Apremilast List Results. Bethesda, MD: US National Library of Medicine. Available from: http://www.clinicaltrials.gov/ct2/results?term=Apremilast\&Sear ch=Search. Accessed November 26, 2012.

49. Papp KA, Kaufmann R, Thaçi D, Hu C, Sutherland D, Rohane P. Efficacy and safety of apremilast in subjects with moderate to severe plaque psoriasis: results from a phase II, multicenter, randomized, double-blind, placebo-controlled, parallel-group, dose-comparison study. J Eur Acad Dermatol Venereol. Epub October 3, 2012.

50. Papp K, Cather JC, Rosoph L, et al. Efficacy of apremilast in the treatment of moderate to severe psoriasis: a randomised controlled trial. Lancet. 2012;380(9843):738-746.

51. Schett G, Wollenhaupt J, Papp K, et al. Oral apremilast in the treatment of active psoriatic arthritis: results of a multicenter, randomized, double-blind, placebo-controlled study. Arthritis Rheum. 2012; 64(10):3156-3167.

52. Gottlieb AB, Strober B, Krueger JG, et al. An open-label, single-arm pilot study in patients with severe plaque-type psoriasis treated with an oral anti-inflammatory agent, apremilast. Curr Med Res Opin. 2008;24(5):1529-1538.
53. Burton PR, Clayton DG, Cardon LR, et al; for Wellcome Trust Case Control Consortium; Australo-Anglo-American Spondylitis Consortium (TASC), Biologics in RA Genetics and Genomics Study Syndicate (BRAGGS) Steering Committee. Association scan of 14,500 nonsynonymous SNPs in four diseases identifies autoimmunity variants. Nat Genet. 2007;39(11):1329-1337.

54. Reveille JD, Sims AM, Danoy P, et al; for Australo-Anglo-American Spondyloarthritis Consortium (TASC). Genome-wide association study of ankylosing spondylitis identifies non-MHC susceptibility loci. Nat Genet. 2010;42(2):123-127.

55. Pathan E, Abraham S, Van Rossen E, et al. Efficacy and safety of apremilast, an oral phosphodiesterase 4 inhibitor, in ankylosing spondylitis. Ann Rheum Dis. Epub September 14, 2012.

56. Schett G, Hayer S, Zwerina J, Redlich K, Smolen JS. Mechanisms of disease: the link between RANKL and arthritic bone disease. Nat Clin Pract Rheumatol. 2005;1(1):47-54.

57. Kim HR, Lee SH, Kim HY. Elevated serum levels of soluble receptor activator of nuclear factors-kappaB ligand (sRANKL) and reduced bone mineral density in patients with ankylosing spondylitis (AS). Rheumatology (Oxford). 2006;45(10):1197-1200.

58. ClinicalTrials.gov [webpage on the Internet]. Search of: apremilast: Phase 3 - List Results. Bethesda, MD: US National Library of Medicine. Available from: http://www.clinicaltrials.gov/ct2/results?term=apremil ast $\&$ recr $=\& \mathrm{rslt}=\&$ type $=\&$ cond $=\&$ intr $=\&$ outc $=\&$ spons $=\& l e a d=\& \mathrm{id}=\&$ state $1=\&$ cntry $1=\&$ state $2=\&$ cntry $2=\&$ state $3=\&$ cntry $3=\& l o c n=\&$ gndr $=$ $\&$ phase=2\&rcv_s=\&rcv_e=\&lup_s=\&lup_e=. Accessed November 26, 2012.

59. Samrao A, Berry TM, Goreshi R, Simpson EL. A pilot study of an oral phosphodiesterase inhibitor (apremilast) for atopic dermatitis in adults. Arch Dermatol. 2012;148(8):890-897.

60. Paul J, Foss CE, Hirano SA, Cunningham TD, Pariser DM. An open-label pilot study of apremilast for the treatment of moderate to severe lichen planus: A case series. J Am Acad Dermatol. 2013;68(2):255-261.

61. Volf EM, Au SC, Dumont N, Scheinman P, Gottlieb AB. A phase 2, open-label, investigator-initiated study to evaluate the safety and efficacy of apremilast in subjects with recalcitrant allergic contact or atopic dermatitis. J Drugs Dermatol. 2012;11(3):341-346.

62. De Souza A, Strober BE, Merola JF, Oliver S, Franks AG Jr. Apremilast for discoid lupus erythematosus: results of a phase 2, openlabel, single-arm, pilot study. J Drugs Dermatol. 2012;11(10): $1224-1226$

63. Bren L. Psoriasis: more than cosmetic. FDA Consumer. 2004 Sept-Oct. Available from: http://permanent.access.gpo.gov/lps1609/www.fda.gov/ fdac/features/2004/504_psoriasis.html. Accessed February 8, 2013.
Drug Design, Development and Therapy

\section{Publish your work in this journal}

Drug Design, Development and Therapy is an international, peerreviewed open-access journal that spans the spectrum of drug design and development through to clinical applications. Clinical outcomes, patient safety, and programs for the development and effective, safe, and sustained use of medicines are a feature of the journal, which

\section{Dovepress}

has also been accepted for indexing on PubMed Central. The manuscript management system is completely online and includes a very quick and fair peer-review system, which is all easy to use. Visit http://www.dovepress.com/testimonials.php to read real quotes from published authors 